\title{
Beyond Climate Impacts: Knowledge Gaps and Process-Based Reflection on Preparing a Regional Chapter for the Fourth National Climate Assessment
}

\author{
Gabrielle Roesch-McNally, ${ }^{\mathrm{a}}$ Michael Chang, ${ }^{\mathrm{b}}$ Meghan Dalton, ${ }^{\mathrm{c}}$ Scott Lowe, ${ }^{\mathrm{d}}$ \\ Charlie Luce, ${ }^{\mathrm{e}}$ Christine May, ${ }^{\mathrm{f}}$ Gary Morishima, ${ }^{\mathrm{g}}$ Philip Mote, ${ }^{\mathrm{c}, \mathrm{h}}$ \\ AleXANDER "SASCHA" Petersen, ${ }^{i}$ AND EMILY YORK ${ }^{j}$ \\ ${ }^{a}$ American Farmland Trust, Washington, D.C. \\ ${ }^{\mathrm{b}}$ Cascadia Consulting Group, Seattle, Washington \\ ${ }^{\mathrm{c}}$ Oregon Climate Change Research Institute, Oregon State University, Corvallis, Oregon \\ ${ }^{\mathrm{d}}$ Boise State University, Boise, Idaho \\ ${ }^{\mathrm{e}}$ Rocky Mountain Research Station, U.S. Forest Service, Boise, Idaho \\ ${ }^{\mathrm{f}}$ Silvestrum Climate Associates, LLC, San Francisco, California \\ ${ }^{\mathrm{g}}$ Quinault Management Center, Bellevue, Washington \\ ${ }^{\text {h }}$ Climate Impacts Research Consortium, Oregon State University, Corvallis, Oregon \\ ${ }^{\mathrm{i}}$ Adaptation International, LLC, Austin, Texas \\ ${ }^{\mathrm{j}}$ Oregon Health Authority, Salem, Oregon
}

(Manuscript received 20 May 2019, in final form 13 February 2020)

\begin{abstract}
The Fourth National Climate Assessment (NCA4) provided the most up-to-date understanding of climate change and its effects on the Earth system and on consequences for the United States, including impacts and associated risks, along with approaches to coping with these effects. It is intended to provide guidance to decision-makers in governmental sectors while, in practice, providing guidance for nongovernmental actors. Its regional and topical chapters highlight current knowledge, uncertainties, gaps in knowledge, and emerging threats. The current knowledge and gaps can help set a research agenda to inform future national, regional, and local climate assessments and thereby support better decision-making. The evolution of the assessment, including greater diversity in participation, and more grounded research in the Northwest represents a growing and deepening engagement with more diverse participants. This shift emphasizes the importance of diversity, inclusion, and a greater acknowledgment of multiple ways of knowing, including local and Indigenous knowledge. The Northwest chapter reflects the broader shift in framing from NCA3 to NCA4 to better understand how climate impacts pose risks to things of value in each sector or region. It considers climate impacts through five broad ways in which humans relate to the environment: natural resource economy; heritage and quality of life; water, transportation, and infrastructure; health and social systems; and frontline communities. We reflect on the assessment process and identify three recommendations to improve the assessment outcomes and processes: seek new ways to 1) engage diverse authors and stakeholders and 2) value and integrate epistemic plurality and different knowledge systems, and 3) when gaps are identified, promote research or data collection efforts designed to fill those gaps. Done well, the assessment can build support and knowledge to facilitate community action, leading to broader resilience.
\end{abstract}

\section{Introduction}

The Fourth National Climate Assessment (NCA4) includes Volume I, the Climate Science Special Report (Wuebbles et al. 2017), and Volume II, Impacts, Risks, and Adaptation in the United States (Reidmiller et al. 2018). The Global Change Research Act of 1990 requires that the

Corresponding author: Gabrielle Roesch-McNally, groeschmcnally@ farmland.org
U.S. Global Change Research Program (USGCRP) deliver a National Climate Assessment to Congress and the U.S. president every 4 years. This paper reflects on the development of the NCA4 Volume II Northwest regional chapter, in which innovative approaches led to a stronger assessment and to insights that may prove useful to the next NCA and other environmental assessments.

Scientific assessments, such as NCA4, provide an opportunity to bring together subject-matter experts to produce syntheses that illustrate scientific consensus on 
the causes and consequences of global phenomena such as climate change (Moss et al. 2019). One of the benefits of developing an assessment process is that it can help facilitate "deliberative policy learning" through a "multi-stakeholder process for distilling and synthesizing knowledge in particular fields to inform policy, [by] involving (regionally and intellectually) diverse experts and stakeholders" (Kowarsch et al. 2016, p. 3). The Northwest experience illustrates the crucial importance of pursuing true intellectual diversity. During the 30 years since the first IPCC assessment, the audience for international, national, regional, and even smaller-scale climate assessments has expanded not just in numbers but also in their expectations to be able to use an assessment in guiding decisions, and in their depth of knowledge of the subject. This iterative process of developing and applying assessment reports and growing the audience for the reports has logically led to a clear need to fully engage that audience in shaping an assessment report. In other words, the model of using academic experts to transmit knowledge to an audience is being upended and replaced by collaborative partnerships among experts whose knowledge originates both from academic pursuits and from practical sources.

In the case of NCA4, stakeholder engagement processes are critical for grounding assessments in the communities, sectors, and industries most affected by climate change to contribute to the continuous dialogue of informed and effective policy or planning decisionmaking (Yamineva 2017). An inclusive process of stakeholder engagement was an explicit expectation of USGCRP, and yet there are still challenges with achieving an optimal level of engagement and representation. For example, not all stakeholders, either groups or individuals, have the same capacity to be engaged in scientific assessments (Kowarsch et al. 2016). Thus, the process itself raises questions about whether and how current assessment processes may reproduce extant power structures, as some individuals and organizations that have greater awareness, access, capacity, and buy-in are more empowered to participate and influence the assessment process. Over time, engagement processes in scientific assessments have received closer scrutiny (Kowarsch et al. 2016; Yamineva 2017; Minx et al. 2017) as there is a growing interest in engaging stakeholders in a multiphase process of developing scientific knowledge (Roesch-McNally and Prendeville 2017). Acknowledging and integrating different knowledge systems can also improve assessment processes and lead to better social and environmental outcomes (Dietz and Stern 2008), which has salience in the context of climate change adaptation and mitigation.
Moreover, beyond just engaging those who intend to use the assessment results for decisions, social justice concerns have also led to expanding the participation to what we call frontline communities. These include tribal and Indigenous communities, low-income urban communities, migrant farmworkers, and other groups who are often most vulnerable to the impacts of climate change and have fewer resources to adapt or respond to changes to mitigate harm due to systemic power and governance structures. Fully including such communities is best accomplished by explicitly acknowledging the value of diverse ways of knowing, including Indigenous and local knowledge (ILK), or epistemic pluralism, "where different ways of acquiring knowledge about the world, including the use of non-scientific perspectives" are included (Yamineva 2017, p. 245). In fact, fully acknowledging the value of different knowledge systems also has the benefit of creating the collaborative partnerships discussed just above. Several chapters (regional as well as the "Tribes and Indigenous Peoples" chapter) integrated ILK in their work. In the Northwest, NCA4 provided an opportunity to expand participation and rethink the model for how we integrate ILK in ways that have rarely been done in previous assessment reports. Inclusion of such diverse views-especially if stakeholders are supported to participate-in assessments can build on the goals of deliberative democracy by creating broader legitimacy and buy-in (Stevenson and Dryzek 2012) as well as honing the usefulness of the assessment.

While the NCA process is framed as an information synthesis effort rather than an effort to prescribe policy, the outputs from the assessment provide a scientific framework that can be used to inform policy and planning at national and subnational levels. The process brings together the most comprehensive documentation of scientific understanding regarding emergent threats, complex interactions, and impacts of climate stressors, which may help decision-makers direct resources, policy, or other planning efforts. Therefore, one of the goals of stakeholder engagement for scientific assessments is to integrate nonscientific actors (or those lacking formal scientific education) in the process of producing knowledge that can inform planning, policy, or future efforts (Rittel and Webber 1973; Howarth and Painter 2016).

This retrospective analysis considers our experience from the Northwest chapter of NCA4 Volume II, in which we highly valued stakeholder engagement and diverse knowledge systems that we contend produced a more robust, useful, broad assessment, and explores the following questions, each in a section: 
1) In what ways does the NCA process encourage, and in what ways does it limit, diverse stakeholder engagement?

2) In what ways does the NCA process support, as well as limit, inclusion of diverse knowledge systems and epistemologies?

3) What gaps exist in the research process and data collection approach that, if addressed, would improve our understanding of regional climate impacts across diverse sectors?

The overall objective of this retrospective is to enable a more robust and inclusive National Climate Assessment by examining how the Northwest chapter was developed, specifically the efforts at stakeholder engagement and integration of diverse knowledge systems. We do not rigorously compare NCA4 processes at the chapter level or the report level (as in Morgan et al. 2005). Instead, this article integrates research used in the preparation of the Northwest chapter of Volume II and the authors' reflections on the dynamics of the assessment process. The work presented in this paper is based on the collective reflection on the process and literature assessment undertaken by the Northwest chapter authors and was not directed by USGCRP. Furthermore, a collaborative workshop session on the Northwest chapter, facilitated by the authors, was hosted at the 2018 Northwest Climate Conference in Boise, Idaho, and was also integrated throughout this retrospective (Roesch-McNally et al. 2018).

\section{Assessment process}

\section{a. Diversity of authors}

The Northwest chapter author team ${ }^{1}$ represents a team carefully selected for balance in discipline, career stage, gender, race, affiliation, and expertise. Authors' affiliations include federal agencies, universities, consulting firms, and tribal governments. Their expertise includes climate change science, social science, economics, public health, tribes and Indigenous peoples, frontline communities, climate adaptation, agriculture, forestry, hydrology, coastal and ocean topics, and ecology. Chapter leaders selected this highly diverse and complementary group of authors from among a pool of nominations and filled gaps by seeking others as well. As diverse as the team was, it could have been more diverse

\footnotetext{
${ }^{1}$ For more detail on the authorship model, author selection process, and broader NCA4 development process, see Avery et al. (2018, their Appendix I: Report Development Process of NCA4, Vol. II).
}

had additional efforts been made to reach authors less connected to regional climate activities; additional obstacles may have included the time commitment and the perception that assessments are highly scientific and technical, which may exclude experts or knowledge holders, especially from an ILK perspective, whose expertise could provide value-added perspectives and information (Mason et al. 2012; Vinyeta and Lynn 2013).

The authors' professional and disciplinary diversity of perspectives directly informed the Northwest chapter's key messages, in particular its view of risks of climate change impacts and adaptation and its focus on frontline communities. The Northwest chapter departed from previous regional NCA reports (e.g., Mote et al. 1999; Dalton et al. 2013), adopting a novel approach for this assessment, which informed other regional chapters through coordinating across regional chapter teams and was specifically organized around differing perspectives on the complex interaction among humans, the natural environment, and climate change, namely,1) reliance on natural resources for livelihoods, 2) natural and cultural heritage, 3) the built environment, 4) health, and 5) frontline communities, which formed the structure of our key messages.

\section{b. Benefits and limitations of stakeholder engagement}

As part of the assessment process, regional stakeholder engagement meetings were hosted across all 10 NCA4 regions, with the goal of purposefully engaging stakeholders at the beginning of the NCA4 process (Luce et al. 2017). In the Northwest, meetings were held on 21 March 2017 in Portland, Oregon, and on 23 March 2017 in Boise, Idaho (Luce et al. 2017). The primary objective of the meetings was to gather input from a diverse array of over 150 participants from the Northwest to inform the Northwest chapter's framing and to raise awareness about the NCA4 timeline and process. The meetings included presentations on regional climate impacts and facilitated breakout groups organized by USGCRP and informed by the stakeholders who were present. Breakout groups were focused on key areas of interest, including water resources, agriculture and rural issues, natural resource management, human dimensions and public health, and environmental impacts.

These conversations were rich with perspectives representative of the diverse attendees from a variety of sectors, including local, state, and federal agencies, tribal governments, university researchers, and nonprofit organizations. Stakeholder engagement workshop announcements, however, were distributed in an ad hoc fashion and recruitment was based on a convenience sample of participants, potentially excluding individuals 
who are not already receiving USGCRP communications or linked into the authors' organizational and professional networks.

Stakeholder participants in the Northwest engagement workshops provided critical feedback regarding local experiences or concerns about climate impacts, scientific literature and technical inputs, and important regional case studies of climate impacts and adaptation that the authors considered when identifying salient examples to include in the chapter. Furthermore, one of the key outcomes of the stakeholder engagement meetings was the shift in the Northwest chapter's framing from the authors' original framing, articulated before the stakeholder engagement meetings, focused around subregional cultures and impacts (i.e., coastal, western lowlands, mountains, and inland) to a collective regional identity and values-based framing (e.g., outdoor recreation, rural food systems, hunting and fishing, and tribal and Indigenous cultures). Understanding how climate change will affect the things that Northwest residents value can inform and prioritize strategic actions to reduce projected impacts (Dietz 2013).

Participants including authors and USGCRP staff viewed the workshops and engagement process very positively; beyond informing the chapter, attendees appreciated the opportunity to cultivate new relationships, research ideas, and future collaborations (Luce et al. 2017). Though there are other forums for such interactions, participants and conceivably the assessment itself could benefit from additional engagement. Balancing the desire for sustained stakeholder engagement and iterative development of chapter content including a synthesis of relevant local examples with the need to meet strict deadlines remains a challenge in any assessment process.

An accomplishment of the stakeholder engagement process was the representation from tribal and Indigenous communities in the region, who were supported by travel grants from the U.S. Department of the Interior's Bureau of Indian Affairs, and public health representatives, who were provided with travel stipends from the Oregon Health Authority via a cooperative agreement with the Centers for Disease Control and Prevention. However, other stakeholder groups were not as actively recruited and thus not adequately represented. There tended to be a gap in representation from frontline and rural communities (e.g., farmers, farmworkers, community-based organizations, and low-income communities). News media, public presentations, webinars, social media, and other outreach could increase stakeholder awareness of opportunities to participate in the assessment process from beginning to end.
As a result of the comprehensive assessment of literature and our engagement with participants in the regional engagement meetings the Northwest chapter clarified five key messages for the chapter, listed above. Because of the ways in which climate impacts will disproportionately affect frontline communities (e.g., rural place-based communities, Indigenous and tribal peoples, urban poor, and farmworkers), authors made a concerted effort to integrate those communities in the discussion of each key message, providing an exemplary framing of impacts on frontline communities and influencing the language included in the all chapters of the NCA4 through engagement with author leads and USGCRP staff (National Academies of Sciences, Engineering, and Medicine 2018).

USGCRP's sustained assessment process, such as the Science to Climate Action Network (SCAN), recommended by the Independent Advisory Committee on Applied Climate Assessment (Moss et al. 2019), provides multiple iterative opportunities for increased public engagement. This approach is intended to expand diversity and inclusion of participants and authors while developing assessments in order to create more robust, accurate, comprehensive, and relevant products.

\section{Knowledge systems}

There is widespread acceptance that Indigenous and place-based knowledge enhances understanding about climate change and its impacts and provides insights to climate adaptation and mitigation (Huntington 2000; Lynn et al. 2013; Chisholm Hatfield et al. 2018). Despite this acceptance, climate assessments at multiple scales, from regional climate assessments to global climate assessments, have encountered challenges in integrating empirical Western scientific knowledge with relativist, place-based, ILKs (Ford et al. 2012, 2016; Maldonado et al. 2016; Obermeister 2017). The NCA has made substantial efforts to be more inclusive and diverse in both process and content. The Third National Climate Assessment was the first NCA to include a chapter dedicated to tribal and Indigenous peoples (Bennett et al. 2014), and other NCA sustained assessment products, including the Impacts of Climate Change on Human Health assessment (Gamble et al. 2016), includes Indigenous science and perspectives. NCA4 Volume II improved tribal and Indigenous inclusion by having a "Tribes and Indigenous Peoples" chapter (Jantarasami et al. 2018), by allocating funding for tribal representatives to attend the regional stakeholder engagement workshops, and by integrating tribal and Indigenous perspectives in many regional and national-level topic chapters. 
Since the National Climate Assessment must meet legal requirements of a highly influential scientific assessment, ${ }^{2}$ it is held to a higher standard for scientific rigor than other vulnerability assessment efforts by the Information Quality Act. The requirements of the Act direct authors to largely rely on peer-reviewed scientific literature in developing their findings, with the goal of ensuring the report's credibility and validity. This requirement may be reasonable on its face yet it can limit the inclusion of diverse perspectives included in the assessment when information is only available outside the peer-reviewed literature (including, but not limited to, gray literature, planning documents, or white papers) because the information sources that can be included must be evaluated by their utility, transparency, traceability, objectivity, and information integrity and security in order to be included (Lewis et al. 2018).

Despite these improvements in inclusion, structural frameworks that are designed to ensure robust scientific integrity have had unintentional negative effects of including ILK systems and epistemologies. To expand on the point about the Information Quality Act, the Act represents mismatched validation norms by upholding ILKs to the standards of Western scientific peer review, rather than to the local customary standards of validation of ILKs. Furthermore, attitudes vary widely among Indigenous leaders and scholars about whether to share culturally sensitive information, as challenges may arise in translating knowledge from languages, customs, traditions, and practices into language understood and accepted by Western scientists. These challenges often decontextualize ILKs from their historical, cultural, economic, and environmental circumstances and legacies (Ericksen and Woodley 2005). Other similar processes, such as scientific peer review, often reinforce scientific imperialism, colonial legacies, and hierarchical structures that continue to marginalize and exploit ILKs and knowledge holders (Golden et al. 2015; Scassa and Taylor 2017; Whyte 2017; Roesch-McNally et al. 2018), despite the call from the broader scientific community for greater inclusion of ILKs.

Because of the large scale of regional and topical reporting and page limitations in the NCA4, it was not possible to adequately portray the diversity of environmental, economic, and cultural impacts on local

\footnotetext{
${ }^{2}$ This is defined as "influential scientific information that the agency or the Administrator of the Office of Information and Regulatory Affairs in the Office of Management and Budget determines to be a scientific assessment that (i) could have a potentia impact of more than $\$ 500$ million in any year, or (ii) is novel, controversial, or precedent-setting or has significant interagency interest" (NOAA 2014).
}

communities. Macrolevel treatment of ecosystem services, health, natural resource management, and climate adaptation results in homogenization and lack of recognition of the significance and importance of locally relevant diversity. Governance and decision-making power are diverse in their geographic scope and representation, and often large-scale assessments do not provide information relevant at multiple scales of governance, which can reinforce power imbalances in decision-making and governance processes (Cash et al. 2006, p. 7; Salomon et al. 2018). Knowledge scales and how to account for multiple epistemic systems have emerged as challenges in large-scale global assessments [e.g., IPCC, Millennium Ecosystem Assessment, Intergovernmental Platform on Biodiversity and Ecosystem Services (IPBES)], especially regarding structural Western scientific frameworks of complementing positivist information with relativist, locally based information in a system that overwhelmingly favors the former (Ericksen and Woodley 2005).

Additionally, there are many other facets and considerations when incorporating ILKs in Western science assessments, such as establishing methods to analyze and integrate ILKs across spatial and temporal scales, the ethics of the language used to "otherize" ILKs, and the rights of communities to retain the intellectual property rights of ILKs that are integrated into Western science assessments (Climate and Traditional Knowledges Workgroup 2014).

\section{Gaps in the research process and data collection approach}

The task of writing the Northwest chapter allowed the author team to explore the landscape of relevant regional literature and synthesize new research on observed and projected climate change and associated impacts on a variety of sectors. Through the literature review, it was evident that there were gaps in both the research process as well as gaps in what topics are chosen for research, which limited a more complete understanding of regional climate impacts across the Northwest. As part of the assessment, we highlight the following gaps: describing impacts on diverse communities, documenting extreme events and their impacts, linking climate data to complex management decisions, and tracking adaptation efforts.

\section{a. Gaps in accounting for impacts on diverse communities}

Despite remarkable progress on research on climate science and impacts, we found that attention was skewed to describing impacts relevant to well-resourced 
communities: water supply for large cities, forest change of relevance to the timber industry, and coastal threats to mostly high-value properties, to name a few examples. By asking "what are we not reading about," we identified gaps that diminished our ability to assess climate impacts and responses across and within the diverse communities of the Northwest. For instance, social indicators of well-being and quality of life can provide powerful insights into how communities respond to climate impacts and provide guidance on appropriate resilience actions, yet they are inherently locally specific and regionally heterogeneous (Díaz et al. 2015; Hicks et al. 2016). The diversity of locally specific social indicators and their development can create barriers and uncertainty when categorizing, analyzing, or comparing climate change impacts on Northwest communities' well-being and quality of life in an assessment process based on a diversity of indicators (Breslow et al. 2016; Roesch-McNally et al. 2018). Assessing future climate impacts on quality of life and well-being of communities across the Northwest is essential, as many communities, especially frontline communities, are already being adversely impacted by climate change and extreme events (May et al. 2018; Moss et al. 2019).

Further, there is a need to examine the role of intersecting vulnerabilities (along lines of race, socioeconomic class, gender, sexuality, occupation, age distribution, and ability) and response capacities for many frontline communities whose social and economic health and well-being are already compromised due to intersecting social, economic, and ecological drivers (IPCC 2014). For instance, emergency department and urgent care clinic data can be monitored in real time and studied retroactively after a climate-related event (such as to detect increases in heat-related stroke or asthma attacks triggered by poor air quality), but this is only a part of the picture. There is a need to better understand other less acute health effects that do not rise to the level of emergency department room visits (such as mental health impacts of prolonged smoke or drought conditions). Additionally, although there is a well-developed literature on the economic impacts of climate change (see Hsiang et al. 2017; Martinich and Crimmins 2019; EPA 2017), the literature lacks the ability to spatially disaggregate the impacts at the subcounty, city, town, or tribal reservation level(s), specifically impacts to rural and local markets for timber, agricultural products, and fisheries, and most notably on jobs and employment. Job and income loss associated with climate factors, for example, lost tourism and agricultural revenue caused by drought and wildfire smoke, can have a considerable effect on a community's physical and mental health, although this connection could still be expanded upon in the literature (Gonzalez et al. 2018). Improvements in incorporating social indicators in complex systems modeling could help future climate assessments to make more confident statements about the varying climate impacts on communities' health, well-being, and economies (Clarke et al. 2018). Concurrent work is underway with the USGCRP Indicators Interagency Working Group Social Sciences Coordinating Committee ${ }^{3}$ on improving integration of social indicators into the assessment process.

\section{b. Gaps in documenting extreme events and their impacts}

As a highly influential scientific assessment, the NCA4 requires multiple standards to ensure that sources used in the assessment are high quality and credible, which may create a time lag that limits an author team's ability to include critically important information on the impacts of recent extreme hydroclimatological events, such as heat waves, drought, flooding, and wildfires. These impacts are eventually mapped by academics and local and federal governments in order to estimate the related damages and losses (e.g., Smith and Matthews 2015; NOAA 2019) and to estimate the probability of occurrence of the event (e.g., Herring et al. 2019), but studies are often published and available months to years after the fact. For example, the Northwest chapter of NCA4 Volume II incorporated the extreme ranges of drought-related impacts in 2015 as a case study, to illustrate future conditions for the region that are more likely to occur due to climate change [Fig. 1, originally produced in May et al. (2018)]. However, most of the studies and data utilized in our case study were published years after the extreme events of 2015. Further, many of these estimates also do not necessarily consider the cascading consequences and impacts across multiple sectors (including natural resources, jobs, public health; Bell et al. 2016; Clarke et al. 2018) or how the risks may be changing over time.

Given the contemporary nature of extreme events, the news media are often the first to describe and document many of the associated impacts, such as death toll or damage costs. However, media sources often do not meet minimum standards under the Information Quality Act. Moreover, because news media typically report very soon after the event, they may not have access to information available later about the full impacts of an extreme events, impacts that are not publicly

\footnotetext{
${ }^{3}$ For more information, see https://www.globalchange.gov/ browse/indicators, accessed 14 May 2019.
} 


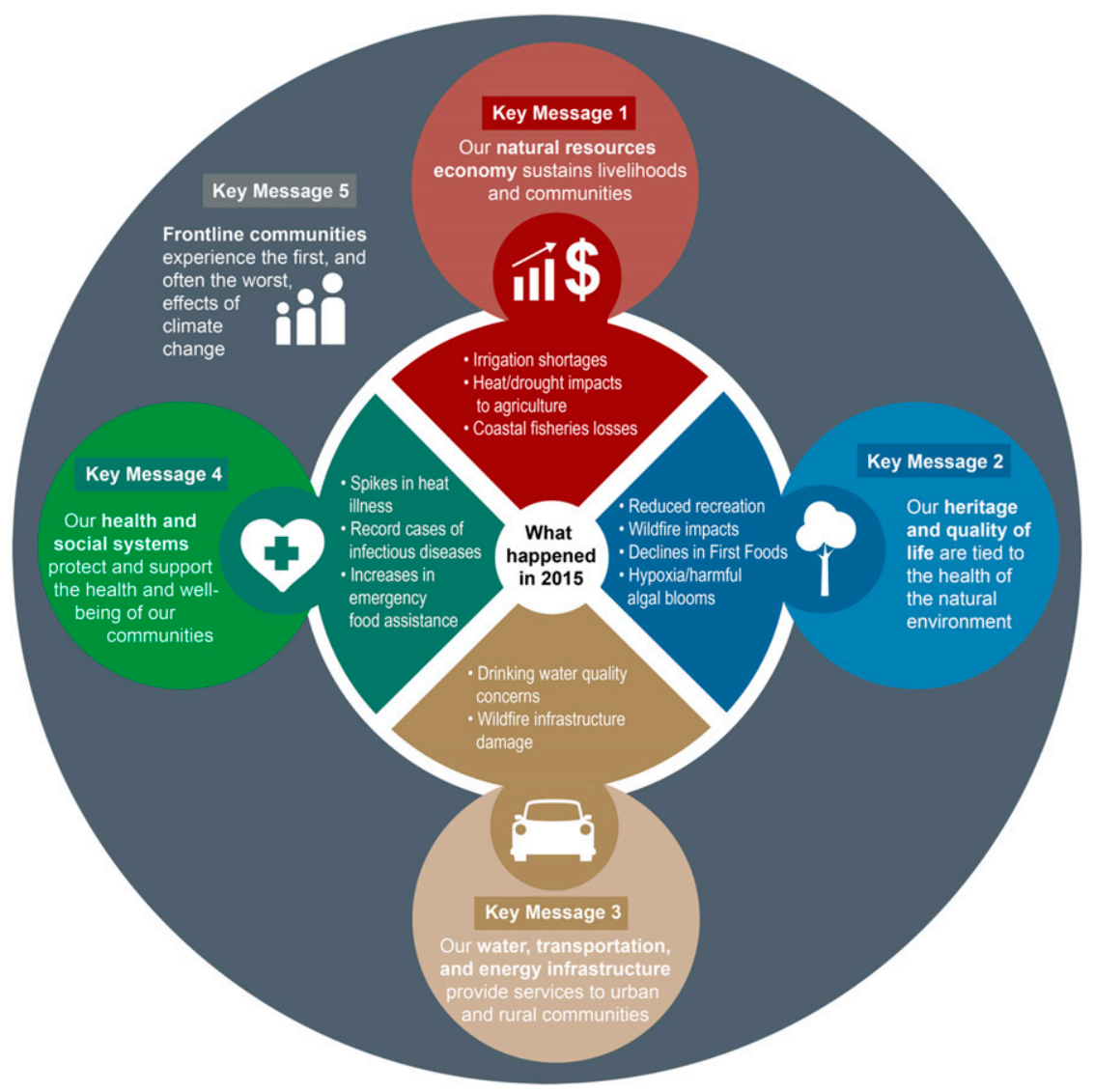

FIG. 1. The climate impacts that occurred during the record-breaking warm and dry year of 2015 highlight the close interrelationships between the climate, the natural and built environment, and the health and well-being of the Northwest's residents. The five key messages highlighted in the Northwest chapter focus on what residents value, and they are just as relevant for the climate-related events of 2015, which presented an extreme drought in the region, and are representative of conditions that are likely to be more common as a result of climate change. Figure reprinted from May et al. (2018).

recorded (e.g., McLain et al. 2017) and often focus on one sector or location. A framework for capturing real-time and cumulative impacts across the region from all sectors and communities would facilitate timely and comprehensive postevent assessments of extreme climate-related events. Some states and sectors are beginning to develop and implement tools and capabilities (e.g., Otkin 2018, and the Drought Impact Reporter). ${ }^{4}$ Sustaining such efforts while engaging a broad array of sectors and communities would facilitate broader coverage of impacts from extreme events in climate assessments, especially for recent extreme events that may have little documentation

\footnotetext{
${ }^{4}$ For more on the Drought Impact Reporter, go to https:// www.drought.gov/drought/data-gallery/drought-impact-reporter, accessed 15 October 2019.
}

and additional difficulties of meeting Information Quality Act (IQA) standards.

\section{c. Gaps in linking climate data to complex management decisions}

Many of the coupled natural resource and climate impacts models fundamentally rely on feedback between management decisions and ecological conditions, yet they rarely integrate feedback relationships as they relate to social systems and policy contexts (Clarke et al. 2018), thus limiting a full understanding of climate consequences on managed ecosystems. Therefore, improving the collective understanding of how changes in management across landscapes and social systems will ultimately affect the resilience of natural resourcebased economies is crucial. Improving our understanding of how these management systems will change as a result of the climate, and vice versa, will help identify 
thresholds beyond which adaptive management may not be enough for mitigating risks (Yorgey et al. 2017; Jorgenson et al. 2018). Improvements to "forecasting thresholds and tipping points of both social and natural systems" (Jorgenson et al. 2018, p. 11) are needed to better prepare communities for threshold-crossing events that require rapid and transformative adaptation (Loboguerrero et al. 2019).

Management decisions are always made in the face of uncertainty, but climate change poses special challenges owing to the fact that it is a "wicked [highly complex and socially intractable] problem" (Lazarus 2008), and the time scales of change appear to be outside the range of much decision-making, though in practice this is not really the case as climate-driven stresses are already occurring. Numerical models of the entire climate system, or of components of it, or of idealized humannatural systems interactions, can provide useful input to decision processes. For example, hydrologic models have been useful for planning (e.g., hydroelectric power) (Safeeq et al. 2015) and crop models can inform crop yields (Stöckle et al. 2018; Karimi et al. 2018; Rajagopalan et al. 2018) and livestock production (Joyce et al. 2013; Neibergs et al. 2017; Mauger et al. 2015). Although complete socioecological systems are often too complex to fully represent in a numerical model, there is a need for continued incremental improvement in the fundamental climate modeling in extending the simulation capability to other processes. For example, in modeling wildfire risk, climate models can confidently project first-order direct impacts such as acres burned. However, these models are still improving how they project indirect and cascading impacts, such as erosion and health impacts from decreased air quality, and incorporate other socioeconomic elements, such as future migration and settlement, risky homeowner behaviors, and policy and management decisions (Clarke et al. 2018).

Understanding pertinent aspects of drought and drought conditions for forest and rangeland managers, especially under a changing climate, is one relevant example in the Northwest of needing to link modeling efforts with management concerns (Clark et al. 2016; Vose et al. 2016, 2018). For example, while forest thinning is an adaptation strategy for forest managers to deal with increasing future drought, it may not be applicable across all forests and conditions, and in certain cases may be unnecessary or maladaptive by generating conditions that reduce net productivity. Improving knowledge of the mechanisms by which drought is affecting forest growth and mortality, specifically around risk or mortality for a given area or species, which might occur via hydraulic failure, starvation, insects, diseases, or fire, is needed for more effective management prescriptions to mitigate climate risk (Vose et al. 2019). Further, understanding complex interactions of changing water balances and heat pathways could help in design of future forests and move past addressing legacy effects of past management to focus on addressing climate adaptation to assist managers in managing their forestland for future conditions (Luce et al. 2016; Phillips et al. 2016; Kolb et al. 2016; Holden et al. 2018).

\section{d. Gaps in tracking adaptation efforts}

A broad solicitation for adaptation case studies included regional stakeholder workshops in Portland, Oregon, and Boise, Idaho; USGCRP's open comment and submission portal that was maintained throughout the assessment process; case studies from the U.S. Climate Resilience Toolkit; and the author team's professional networks. In general, it became evident that adaptation efforts were occurring across multiple sectors throughout the Northwest region that paralleled national efforts. However, many of these actions are not yet common or occurring fast enough, or at the level required, to adequately prepare for the impacts of climate change (Lempert et al. 2018; Moss et al. 2019). Many adaptation strategies remain stalled or focused on the planning phase (e.g., climate vulnerability and risk assessment) and are not yet being implemented (Moser et al. 2017; Lempert et al. 2018).

Few case studies in the Northwest highlight adaptation strategies that have been implemented and monitored for a sufficient length of time in order to assess long-term success in increasing climate resiliency, particularly to changes in extreme events. Pre- and postevent monitoring data are needed to assess the efficacy of adaptation actions at moderating the extreme climate-related impacts (Roesch-McNally et al. 2018). Broader evaluations are also needed to assess the cascading consequences and impacts for economic, social, cultural, and ecological systems. These evaluations are easier to accomplish for smaller-scale adaptation efforts, such as the stream and rearing pond restoration efforts of the Nez Perce Tribe, which enhanced the local salmon fishery and tribal wellbeing and identity (Colombi and Smith 2014).

Additional information is needed to further understand cobenefits of larger-scale adaptation and mitigation efforts. For example, a health impact assessment of the Portland Metro Regional Government's Climate Smart Strategy found that proposed climate actions to reduce greenhouse gas emissions and mitigate climate change could also reduce chronic diseases like cancer, heart disease, stroke, and diabetes by $2 \%-4 \%$ 
(Green et al. 2013). Projects that utilize both quantitative and qualitative data, and that support information sharing and community capacity building among frontline communities, can lead to innovative and effective solutions (Decorby-Watson et al. 2018). The use of locally relevant and, where possible, consistent community resilience indicators could ease the longterm monitoring burden and help quantify adaptation successes occurring across the region and measure the success of those projects in addressing both chronic stressors (e.g., sea level rise) and extreme events (e.g., catastrophic flooding). These kinds of projects can ensure outcomes are evaluated and contribute to the climate adaptation evidence base (Israel et al. 2010).

\section{Recommendations for future assessment products and processes}

This retrospective concludes in providing a framework that could feed into planning and prioritization for future sustained climate assessment efforts, such as the National Climate Assessment, but may be relevant to other regional assessments. As such, we have identified key recommendations, which are centered around the primary themes presented in this paper: 1) engage diverse authors and stakeholders, 2) value and integrate epistemic plurality and different knowledge systems, and 3) when gaps are identified, promote research or data collection efforts designed to fill those gaps. These recommendations are offered to improve sustained participation and buy-in throughout the assessment process to ensure the assessment is useful to governmental, nongovernmental, and community-based organizations.

\section{a. Engage diverse authors and stakeholders}

Similar to the goals of including more diverse knowledge systems in the assessment process, it is important that current stakeholder engagement efforts go further in meeting communities where they are to improve participation in USGCRP assessment processes. This includes making more intentional space and time for more information-sharing, perhaps via social media and other online forums, input-gathering through both in-person and virtual meetings, and sustained interactions that allow for a sharing of assessment findings, such as leveraging and building off the work of the NCAnet (the network of networks supporting the National Climate Assessment; http://ncanet.usgcrp. gov/home). Although such changes can be a challenge to resource, these changes could create a more dynamic engagement with stakeholders throughout the life cycle of the assessment process rather than just at the beginning and improve the diversity of stakeholders represented in final products. Linking national assessment efforts with existing local climate assessments can improve the integration of the NCA to leverage and harmonize assessment work with ongoing localized stakeholder efforts. Further, more attention is needed to involve new and different groups in stakeholder engagement activities that have historically not been linked into the assessment network. The engagement of these groups, which are often frontline communities, may mean having author teams meeting groups and communities where they reside, rather than expecting them to come to regional outreach meetings at a specific time and place. Covering the cost of community-based organizations and leaders from diverse communities to attend workshops or serve as advisors (such as through honoraria or travel stipends) can help to ensure meaningful engagement among groups who otherwise would not have the capacity to participate.

A more comprehensive stakeholder engagement process may help achieve broader goals by informing "issue-framing, information-sharing, buy-in, mutual learning or the communication of assessment findings" (Yamineva 2017, p. 249), particularly if their knowledge can help direct attention to where the data gaps are most severe for their communities and sectors of concern. This may help community-based organizations and other relevant community stakeholders, including citizen science groups, in making climate assessments more relevant in their planning and adaptation efforts (Moss et al. 2019). A local example of climate work being done with a broad coalition of stakeholders is the City of Portland and Multnomah Counties' Climate Action through Equity Plan (Williams-Rajee and Evans 2016) that includes an equity working group made up of representatives from six community-based organizations representing the interests of low-income populations and communities of color to ensure equitable climate action.

To address the concerns associated with engaging diverse representation across the author team and stakeholder engagement processes, the following strategies are suggested: host regional workshops or working groups that specifically engage diverse knowledge holders (Tengö et al. 2017), expand inclusion of holders of ILKs as part of the author teams or report contributors (Ford et al. 2012), and continue a commitment to engaging author team members from diverse disciplines. Finally, building off Minx et al. (2017), there is increased need for integrating more social sciences and humanities in global and regional climate assessment work by specifically organizing research priorities that aggregate diverse knowledge on climate solutions and relevant impacts. Efforts are already underway with USGCRP's Social Sciences Coordinating Committee 
to do this integration work. These efforts illustrate the many ways that USGCRP has been responsive to the evolution of climate science and impacts assessment (Jacobs et al. 2016), while also remaining committed to improving the assessment process by broader engagement with cross-disciplinary scientists, researchers, practitioners, tribal leaders, and citizens who have a stake in accurate and impactful climate assessment work.

There may also be lessons to learn from the public health community as they have established expertise in advancing equity, addressing health disparities, and utilizing best practices in inclusive community engagement to achieve public health goals (Fagliano and Diez Roux 2018). Partnerships between public health and other sectors researching, assessing, and investing in climate adaptation could help to fill gaps in both data collection and engaging a diverse and important stakeholder group. Some local health departments have already begun to successfully engage diverse stakeholders (Grossman et al. 2018) and their role of ensuring equity within assessment, planning, and implementation activities has been clearly defined in recent years (Rudolph et al.2018) and provides potential guidance for other sectors interested in increasing equity in their planning and assessment processes.

\section{b. Value and integrate epistemic plurality and different knowledge systems}

Multiple ethical challenges arise when incorporating ILKs into large scientific assessments (Maldonado et al. 2016). Most prominently, many Indigenous communities often are concerned that sharing their ILKs will perpetuate colonialist processes of extractive methods for further marginalization, where legacies of systems rooted in Western scientific methods lack a recognition of the legitimacy and validity of ILKs and the multigenerational accumulation of knowledge (Berkes et al. 2000; International Society of Ethnobiology 2006). ILKs are developed through local customary laws, traditions, practices, and governance and are often predicated on a contextual and reciprocal relationship between peoples and their environments. Therefore, a good approach for integrating all ILKs should follow the principles of free, prior, and informed consent and intellectual property rights over traditional and cultural knowledge (Mason et al. 2012; Vinyeta and Lynn 2013; Obermeister 2017). Within the Northwest chapter of NCA4 Volume II, all ILKs case studies (see Colombi and Smith 2014; Confederated Tribes of the Umatilla Indian Reservation 2015; Got Green and Puget Sound Sage 2016) were verified with local community practitioners and informed consent was sought, even though these studies were publicly available. Further, one way to improve the integration of ILKs is to capture critically important input in forms that do meet quality requirements, such as the Regional Engagement Workshop (REW) Summary Reports that were created for NCA4, ${ }^{5}$ and it is important that these be designed to ensure equitable participation by individuals representing diverse groups. Participatory scales and processes of coproducing assessments with knowledge holders and local community practitioners are also likely to provide means of empowering and elevating ILKs in assessment processes. Fully intentional collaborative processes, while difficult to achieve, can be facilitated by overcoming logistical and administrative barriers (e.g., compensation, validation of ILKs, representation and equity, controlling narrative of results and outcomes, reciprocity) and can improve participation (Narayan et al. 2000; Cleaver 2001; Ericksen and Woodley 2005). Additionally, it is recommended that USGCRP consider establishing an interagency working group or coordinating committee to create a system for improved integration of ILKs and equity into assessments that addresses these issues of ethics, process, scale, and information quality for ILKs (Roesch-McNally et al. 2018) and may benefit from integration or engagement with existing networks, such as with the Department of Interior's Tribal Climate Liaisons, the United Nations's Permanent Forum on Indigenous Issues, Survival International, and other similar groups (Norton-Smith et al. 2016). Finally, ILKs should be held to the local and customary standards of validation and credibility, not to the standards of Western scientific peer review (Ericksen and Woodley 2005; Obermeister 2017).

\section{c. When gaps are identified, promote research or data collection efforts designed to fill those gaps}

Research efforts that directly address previously identified research gaps should be prioritized. A solution to the challenge of linking previously identified research gaps with current research priorities may be to better utilize the "traceable account" sections at the end of each NCA chapter. Associated with each key message, it articulates major uncertainties that can be harvested to chart future research directions, which is something that the USGCRP is exploring as part of its sustained assessment process. Another important consideration is to continuously engage communities of practice, as a web of long-term, continuous professional relationships, in identifying and filling gaps in

\footnotetext{
${ }^{5}$ The Northwest REW Summary Report is publicly available at https://www.globalchange.gov/sites/globalchange/files/REW_ Northwest.pdf.
} 
knowledge and research over time (Moss et al. 2019), particularly research that helps meet a practical and applied need. Therefore, mapping a research and data collection agenda based on identified gaps across successive NCAs and increasing the stakeholder participation in identifying and filling gaps would help improve the usability of future NCAs and advance the science in some practical ways.

\section{Conclusions}

As climate change information diffuses into society, decision-makers are increasingly aware that the available climate projections are incomplete in practical details and include uncertainties, particularly surrounding how these changes will impact the things that people care about. Therefore, comprehensive assessments such as the NCA are critical for making clear linkages between the most up-to-date climate research and the needs of those who must respond to change in the face of uncertainty and imperfect information. This retrospective provides key guidance on how to improve our process of engaging diverse stakeholders and authors in the writing of future assessments, as well as strategies for integrating ILKs into our assessment of what is known about impacts and projected changes. Finally, our work highlights key gaps in the research process and articulates the need to better target research prioritization as an outcome associated with the work of the assessments. The NCA and its process has evolved over its different iterations and is something to be appreciated and fully acknowledged. Therefore, our work here provides further guidance on how the next iteration of the NCA, and other regional assessments, might create assessment products that continue to meet the diversity of needs to better prepare multiple publics for climatic changes that are already occurring and will continue to do so.

Acknowledgments. Thank you to USGCRP and Dr. Dave Reidmiller for their friendly review of our article. We would also like to thank all our coauthors from the Northwest chapter, not all of whom were able to join this manuscript effort. And finally, thanks to all the many researchers, agency leaders, community members, and tribal leaders who make the National Climate Assessment what it is and continue to help build it into what it can be. We also appreciate the input and additions from three anonymous reviewers.

\section{REFERENCES}

Avery, C. W., D. R. Reidmiller, T. S. Carter, K. L. M. Lewis, and K. Reeves, 2018: Report development process. Impacts, Risks, and Adaptation in the United States: Fourth National Climate
Assessment, Vol. II, D. R. Reidmiller et al., Eds., U.S. Global Change Research Program, 1387-1409, https://doi.org/ 10.7930/NCA4.2018.AP1.

Bell, J. E., and Coauthors, 2016: Impacts of extreme events on human health. The Impacts of Climate Change on Human Health in the United States: A Scientific Assessment, U.S. Global Change Research Program, 99-128, https://doi.org/ 10.7930/J0BZ63ZV.

Bennett, T. M. B., and Coauthors, 2014: Indigenous peoples, lands, and resources. Climate Change Impacts in the United States: The Third National Climate Assessment, J. M. Melillo, T. T. C. Richmond, and G. W. Yohe, Eds., U.S. Global Change Research Program, 297-317, https://doi.org/10.7930/ J09G5JR1.

Berkes, F., J. Colding, and C. Folke, 2000: Rediscovery of traditional ecological knowledge as adaptive management. Ecol. Appl., 10, 1251-1262, https://doi.org/10.1890/1051-0761(2000) 010[1251:ROTEKA]2.0.CO;2.

Breslow, S. J., and Coauthors, 2016: Conceptualizing and operationalizing human wellbeing for ecosystem assessment and management. Environ. Sci. Policy, 66, 250-259, https://doi.org/ 10.1016/j.envsci.2016.06.023.

Cash, D., W. N. Adger, F. Berkes, P. Garden, L. Lebel, P. Olsson, L. Pritchard, and O. Young, 2006: Scale and cross-scale dynamics: Governance and information in a multilevel world. Ecol. Soc., 11, 8, https://doi.org/10.5751/ES-01759-110208.

Chisholm Hatfield, S., E. Marino, K. P. Whyte, K. D. Dello, and P. W. Mote, 2018: Indian time: Time, seasonality, and culture in traditional ecological knowledge of climate change. Ecol. Process., 7, 25, https://doi.org/10.1186/s13717-018-0136-6.

Clark, J. S., J. M. Vose, and C. H. Luce, 2016: Forest drought as an emerging research priority. Global Change Biol., 22, 2317, https://doi.org/10.1111/gcb.13252.

Clarke, L., and Coauthors, 2018: Sector interactions, multiple stressors, and complex systems. Impacts, Risks, and Adaptation in the United States: Fourth National Climate Assessment, Vol. II, D. R. Reidmiller et al., Eds., U.S. Global Change Research Program, 638-668, https://doi.org/10.7930/NCA4.2018.CH17.

Cleaver, F., 2001: Institutions, agency and the limitations of participatory approaches to development. Participation: The New Tyranny?, B. Cooke and U. Kothari, Eds., Zed Books, 36-55.

Climate and Traditional Knowledges Workgroup, 2014: Guidelines for considering traditional knowledges in climate change initiatives, version 1. CTKW, 109 pp., https://climatetkw. files.wordpress.com/2018/05/tks_guidelines_v1.docx.

Colombi, B. J., and C. L. Smith, 2014: Insights on adaptive capacity: Three indigenous Pacific Northwest historical narratives. J. Northwest Anthropol., 48, 189-201.

Confederated Tribes of the Umatilla Indian Reservation, 2015: Climate change vulnerability assessment. CTUIR-DOSE, 79 pp., https:// static1.squarespace.com/static/50c23e29e4b0958e038d6bd6/ t/57b4c5af6a496315610b2d86/1471464889144/CTUIR + Vulnerability+Assessment+Technical+Report+FINAL.pdf.

Dalton, M. M., P. W. Mote, and A. K. Snover, Eds., 2013: Climate Change in the Northwest: Implications for Our Landscapes, Waters, and Communities. Island Press, $271 \mathrm{pp}$.

Decorby-Watson, K., G. Mensah, K. Bergeron, S. Abdi, B. Rempel, and H. Manson, 2018: Effectiveness of capacity building interventions relevant to public health practice: A systematic review. BMC Public Health, 18, 684, https:// doi.org/10.1186/s12889-018-5591-6.

Díaz, S., and Coauthors, 2015: The IPBES conceptual framework-Connecting nature and people. Curr. Opin. 
Environ. Sustain., 14, 1-16, https://doi.org/10.1016/j.cosust. 2014.11.002.

Dietz, T., 2013: Bringing values and deliberation to science communication. Proc. Natl. Acad. Sci. USA, 110, 14 081-14 087, https://doi.org/10.1073/pnas.1212740110.

——, and P.C. Stern, Eds., 2008: Public Participation in Environmental Assessment and Decision Making. National Academies Press, 306 pp., https://doi.org/10.17226/12434.

EPA, 2017: Multi-model framework for quantitative sectoral impacts analysis: A technical report for the Fourth National Climate Assessment. U.S. Environmental Protection Agency Rep. EPA 430-R-17-001, 277 pp., https://cfpub.epa.gov/si/si_public_file_ download.cfm?p_download_id $=537327 \&$ Lab $=$ OAP.

Ericksen, P., and E. Woodley, 2005: Using multiple knowledge systems: Benefits and challenges. Ecosystems and Human Well-Being: Multiscale Assessments, Vol. 4, D. Capistrano et al., Eds., Island Press, 85-117.

Fagliano, J. A., and A. V. Diez Roux, 2018: Climate change, urban health, and the promotion of health equity. PLoS Med., 15, e1002621, https://doi.org/10.1371/journal.pmed.1002621.

Ford, J. D., W. Vanderbilt, and L. Berrang-Ford, 2012: Authorship in IPCC AR5 and its implications for content: Climate change and indigenous populations in WGII. Climatic Change, 113, 201-213, https://doi.org/10.1007/s10584-011-0350-z.

—, L. Cameron, J. Rubis, M. Maillet, D. Nakashima, A. C. Willox, and T. Pearce, 2016: Including indigenous knowledge and experience in IPCC assessment reports. Nat. Climate Change, 6, 349-353, https://doi.org/10.1038/nclimate2954.

Gamble, J. L., and Coauthors, 2016: Populations of concern. The Impacts of Climate Change on Human Health in the United States: A Scientific Assessment, U.S. Global Change Research Program, 247-286, https://doi.org/10.7930/J0Q81B0T.

Golden, D. M., C. Audet, and M. A. Smith, 2015: "Blue-ice": Framing climate change and reframing climate change adaptation from the indigenous peoples' perspective in the northern boreal forest of Ontario, Canada. Climate Dev., 7, 401-413, https://doi.org/10.1080/17565529.2014.966048.

Gonzalez, P., and Coauthors, 2018: Southwest. Impacts, Risks, and Adaptation in the United States: Fourth National Climate Assessment, Vol. II, D. R. Reidmiller et al., Eds., U.S. Global Change Research Program, 1101-1184, https://doi.org/10.7930/ NCA4.2018.CH25.

Got Green and Puget Sound Sage, 2016: Our people, our planet, our power-Community led research in south Seattle. Got Green, 51 pp., http:/gotgreenseattle.org/wp-content/uploads/2016/03/ OurPeopleOurPlanetOurPower_GotGreen_Sage_Final1.pdf.

Green, M., A. Hamberg, E. Main, J. Early-Alberts, N. Dubuisson, and J. P. Douglas, 2013: Climate Smart Communities Scenarios: Health impact assessment. Oregon Health Authority Rep., 64 pp., https://www.oregon.gov/oha/ph/HealthyEnvironments/ TrackingAssessment/HealthImpactAssessment/Documents/CSCS/ FINAL_Climate\%20Smart\%20Communities\%20Scenarios.pdf.

Grossman, E., and Coauthors, 2018: Minigrants to local health departments: An opportunity to promote climate change preparedness. J. Public Health Manag. Pract., 25, 113-120, https://doi.org/10.1097/PHH.0000000000000826.

Herring, S. C., N. Christidis, A. Hoell, M. P. Hoerling, and P. A. Stott, Eds., 2019: Explaining Extreme Events of 2017 from a Climate Perspective. Bull. Amer. Meteor. Soc., 100 (1), S1-S117, https:// doi.org/10.1175/BAMS-ExplainingExtremeEvents2017.1.

Hicks, C. C., and Coauthors, 2016: Engage key social concepts for sustainability. Science, 352, 38-40, https://doi.org/10.1126/ science.aad4977.
Holden, Z. A., and Coauthors, 2018: Decreasing fire season precipitation increased recent western U.S. forest wildfire activity. Proc. Natl. Acad. Sci. USA, 115, E8349-E8357, https:// doi.org/10.1073/pnas.1802316115.

Howarth, C., and J. Painter, 2016: Exploring the science-policy interface on climate change: The role of the IPCC in informing local decision-making in the UK. Palgrave Commun., 2, 16058, https://doi.org/10.1057/palcomms.2016.58.

Hsiang, S., and Coauthors, 2017: Estimating economic damage from climate change in the United States. Science, 356, 1362-1369, https://doi.org/10.1126/science.aal4369.

Huntington, H. P., 2000: Using traditional ecological knowledge in science: methods and applications. Ecol. Appl., 10, 1270-1274, https://doi.org/10.1890/1051-0761(2000)010[1270:UTEKIS] 2.0.CO;2.

International Society of Ethnobiology, 2006: International Society of Ethnobiology Code of Ethics (with 2008 additions). ISE, accessed 30 April 2019, http://ethnobiology.net/code-of-ethics/.

IPCC, 2014: Summary for policymakers. Climate Change 2014: Impacts, Adaptation, and Vulnerability. Part A: Global and Sectoral Aspects, C. B. Field et al., Eds., Cambridge University Press, 32 pp., https://www.ipcc.ch/site/assets/uploads/2018/02/ ar5_wgII_spm_en.pdf.

Israel, B., and Coauthors, 2010: Community-based participatory research: A capacity-building approach for policy advocacy aimed at eliminating health disparities. Amer. J. Public Health, 100, 2094-2102, https://doi.org/10.2105/AJPH.2009.170506.

Jacobs, K. L., J. L. Buizer, S. C. Moser, and A. Britson, 2016: The third US national climate assessment: Innovations in science and engagement. Climatic Change, 135, 1-7, https://doi.org/ 10.1007/s10584-016-1621-5.

Jantarasami, L. C., and Coauthors, 2018: Tribes and indigenous peoples. Impacts, Risks, and Adaptation in the United States: Fourth National Climate Assessment, Vol. II, D. R. Reidmiller et al., Eds., U.S. Global Change Research Program, 572-603, https://doi.org/10.7930/NCA4.2018.CH15.

Jorgenson, A. K., and Coauthors, 2018: Social science perspectives on drivers of and responses to global climate change. Wiley Interdiscip. Rev.: Climate Change, 10, e554, https://doi.org/ 10.1002/WCC.554.

Joyce, L. A., D. D. Briske, J. R. Brown, H. W. Polley, B. A. McCarl, and D. W. Bailey, 2013: Climate change and North American rangelands: Assessment of mitigation and adaptation strategies. Rangeland Ecol. Manage., 66, 512-528, https://doi.org/ 10.2111/REM-D-12-00142.1.

Karimi, T., C. O. Stockle, S. Higgins, and R. Nelson, 2018: Climate change and dryland wheat systems in the US Pacific Northwest. Agric. Syst., 159, 144-156, https://doi.org/10.1016/ j.agsy.2017.03.014.

Kolb, T. E., C. J. Fettig, M. P. Ayres, B. J. Bentz, J. A. Hicke, R. Mathiasen, J. E. Stewart, and A. S. Weed, 2016: Observed and anticipated impacts of drought on forest insects and diseases in the United States. For. Ecol. Manage., 380, 321-334, https://doi.org/10.1016/j.foreco.2016.04.051.

Kowarsch, M., J. Garard, P. Riousset, D. Lenzi, M. J. Dorsch, B. Knopf, J. A. Harrs, and O. Edenhofer, 2016: Scientific assessments to facilitate deliberative policy learning. Palgrave Commun., 2, 16092, https://doi.org/10.1057/palcomms.2016.92.

Lazarus, R. J., 2008: Super wicked problems and climate change: Restraining the present to liberate the future. Cornell Law Rev., 94, 1153-1234.

Lempert, R., J. Arnold, R. Pulwarty, K. Gordon, K. Greig, C. Hawkins Hoffman, D. Sands, and C. Werrell, 2018: 
Reducing risks through adaptation actions. Impacts, Risks, and Adaptation in the United States: Fourth National Climate Assessment, Vol. II, D. R. Reidmiller et al., Eds., U.S. Global Change Research Program, 1309-1345, https://doi.org/10.7930/ NCA4.2018.CH28.

Lewis, K. L. M., D. R. Reidmiller, and C. W. Avery, 2018: Information in the Fourth National Climate Assessment. Impacts, Risks, and Adaptation in the United States: Fourth National Climate Assessment, Vol. II, D. R. Reidmiller et al., Eds., U.S. Global Change Research Program, 1410-1412, https://doi.org/10.7930/NCA4.2018.AP2.

Loboguerrero, A. M., B. M. Campbell, P. J. Cooper, J. W. Hansen, T. Rosenstock, and E. Wollenberg, 2019: Food and earth systems: Priorities for climate change adaptation and mitigation for agriculture and food systems. Sustainability, 11, 1372, https://doi.org/10.3390/su11051372.

Luce, C. H., J. M. Vose, N. Pederson, J. Campbell, C. Millar, P. Kormos, and R. Woods, 2016: Contributing factors for drought in United States forest ecosystems under projected future climates and their uncertainty. For. Ecol. Manage., 380, 299-308, https://doi.org/10.1016/j.foreco.2016.05.020.

_ - and Coauthors, 2017: Regional Engagement Workshop Summary Report: Northwest region. U.S. Global Change Research Program, 23 pp., https://www.globalchange.gov/ sites/globalchange/files/REW_Northwest.pdf.

Lynn, K., and Coauthors, 2013: The impacts of climate change on tribal traditional foods. Climatic Change, 120, 545-556, https:// doi.org/10.1007/s10584-013-0736-1.

Maldonado, J., and Coauthors, 2016: Engagement with indigenous peoples and honoring traditional knowledge systems. Climatic Change, 135, 111-126, https://doi.org/10.1007/ s10584-015-1535-7.

Martinich, J., and A. Crimmins, 2019: Climate damages and adaptation potential across diverse sectors of the United States. Nat. Climate Change, 9, 397-404, https://doi.org/10.1038/ s41558-019-0444-6.

Mason, L., and Coauthors, 2012: Listening and learning from traditional knowledge and western science: A dialogue on contemporary challenges of forest health and wildfire. J. For., 110, 187-193, https://doi.org/10.5849/JOF.11-006.

Mauger, G., Y. Bauman, T. Nennich, and E. Salathé, 2015: Impacts of climate change on milk production in the United States. Prof. Geogr., 67, 121-131, https://doi.org/10.1080/ 00330124.2014.921017.

May, C., and Coauthors, 2018: Northwest. Impacts, Risks, and Adaptation in the United States: Fourth National Climate Assessment, Vol. II, D. R. Reidmiller et al., Eds., U.S. Global Change Research Program, 1036-1100, https://doi.org/10.7930/ NCA4.2018.CH24.

McLain, K., J. Hancock, and M. Drennan, 2017: Drought and agriculture: A study by the Washington State Department of Agriculture. Washington State Academy of Sciences AGR PUB 104-495, 15 pp., https://agr.wa.gov/FP/Pubs/ docs/495-2015DroughtReport.pdf.

Minx, J. C., M. Callaghan, W. F. Lamb, J. Garard, and O. Edenhofer, 2017: Learning about climate change solutions in the IPCC and beyond. Environ. Sci. Policy, 77, 252-259, https://doi.org/10.1016/j.envsci.2017.05.014.

Morgan, M. G., and Coauthors, 2005: 2005: Learning from the U.S. National Assessment of Climate Change Impacts. Environ. Sci. Technol., 39, 9023-9032, https://doi.org/10.1021/es050865i.

Moser, S. C., J. Coffee, and A. Seville, 2017: Rising to the challenge, together: A review and critical assessment of the state of the US climate adaptation field. Kresge Foundation Rep., 105 pp., https://kresge.org/content/rising-challenge-together.

Moss, R., and Coauthors, 2019: Evaluating knowledge to support climate action: A framework for sustained assessment. Report of an independent advisory committee on applied climate assessment. Wea. Climate Soc., 11, 465-487, https://doi.org/ 10.1175/WCAS-D-18-0134.1.

Mote, P. W., and Coauthors, 1999: Impacts of climate variability and change in the Pacific Northwest. JISAO/SMA Climate Impacts Group, 110 pp.

Narayan, D., R. Chambers, M. Kaul Shah, and P. Petesch, 2000: Voices of the Poor: Crying out for Change. Oxford University Press, 314 pp.

National Academies of Sciences, Engineering, and Medicine, 2018: Review of the Draft Fourth National Climate Assessment. The National Academies Press, 206 pp., https://doi.org/10.17226/25013.

Neibergs, J. S., T. D. Hudson, and C. E. Kruger, and K. H. Rieken, 2017: Estimating climate change effects on grazing management and beef cattle production in the Pacific Northwest. Climatic Change, 146, 5-17, https://doi.org/10.1007/s10584017-2014-0.

NOAA, 2014: National Oceanic and Atmospheric Administration information quality guidelines. Accessed 15 March 2019, https:// www.cio.noaa.gov/services_programs/IQ_Guidelines_103014.html. , 2019: Billion-dollar weather and climate disasters: Overview. Accessed 24 November 2019, https:/www.ncdc.noaa.gov/ billions/overview.

Norton-Smith, K., and Coauthors, 2016: Climate change and indigenous peoples: A synthesis of current impacts and experiences. USDA Forest Service General Tech. Rep. PNW-GTR-944, 136 pp., https://www.fs.fed.us/pnw/pubs/pnw_gtr944.pdf.

Obermeister, N., 2017: From dichotomy to duality: Addressing interdisciplinary epistemological barriers to inclusive knowledge governance in global environmental assessments. Environ. Sci. Policy, 68, 80-86, https://doi.org/10.1016/j.envsci.2016.11.010.

Otkin, J. A., 2018: Comparison of agricultural stakeholder survey results and drought monitoring datasets during the 2016 U.S. northern plains flash drought. Wea. Climate Soc., 10, 867, https://doi.org/10.1175/WCAS-D-18-0051.1.

Phillips, R. P., I. Ibáñez, L. D’Orangeville, P. J. Hanson, M. G. Ryan, and N. G. McDowell, 2016: A belowground perspective on the drought sensitivity of forests: Towards improved understanding and simulation. For. Ecol. Manage., 380, 309-320, https://doi.org/10.1016/j.foreco.2016.08.043.

Rajagopalan, K., and Coauthors, 2018: Impacts of near-term regional climate change on irrigation demands and crop yields in the Columbia River basin. Water Resour. Res., 54, 2152-2182, https://doi.org/10.1002/2017WR020954.

Reidmiller, D. R., C. W. Avery, D. R. Easterling, K. E. Kunkel, K. L. M. Lewis, T. K. Maycock, and B. C. Stewart, Eds., 2018: Impacts, Risks, and Adaptation in the United States: Fourth National Climate Assessment. Vol. II, U.S. Global Change Research Program, 1515 pp., https://doi.org/10.7930/NCA4.2018.

Rittel, H. W. J., and M. M. Webber, 1973: Dilemmas in a general theory of planning. Policy Sci., 4, 155-169, https://doi.org/ 10.1007/BF01405730.

Roesch-McNally, G., and H. R. Prendeville, 2017: Making sense of coproduction: What is it good for? USDA Forest Service How-to Leaflet PNW-HT-001, 4 pp., https://www. climatehubs.oce.usda.gov/sites/default/files/PNW-HT-001.pdf. , and Coauthors, 2018: Beyond climate impacts: Reflections of process and knowledge gaps in preparing for the Northwest regional chapter of the Fourth National Climate Assessment. 
Northwest Climate Conf., Boise, ID, University of Idaho, https:// www.nwclimateconference.org/Boise2018/program.html.

Rudolph, L., C. Harrison, L. Buckley, and S. North, 2018: Climate change, health, and equity: A guide for local health departments. Public Health Institute and American Public Health Association, 376 pp., https://www.apha.org/-/media/files/ pdf/topics/climate/climate_health_equity.ashx?la =en\&hash $=$ 14D2F64530F1505EAE7AB16A9F9827250EAD6C79.

Safeeq, M., G. S. Mauger, G. E. Grant, I. Arismendi, A. F. Hamlet, and S.-Y. Lee, 2015: Comparing large-scale hydrological model predictions with observed streamflow in the Pacific Northwest: Effects of climate and groundwater. J. Hydrometeor., 15, 2501-2521, https://doi.org/10.1175/ JHM-D-13-0198.1.

Salomon, A. K., K. Lertzman, K. Brown, K. B. Wilson, D. Secord, and I. McKechnie, 2018: Democratizing conservation science and practice. Ecol. Soc., 23, 44, https:// doi.org/10.5751/ES-09980-230144.

Scassa, T., and F. Taylor, 2017: Legal and ethical issues around incorporating traditional knowledge in polar data infrastructures. Data Sci. J., 16, 1-14, https://doi.org/10.5334/dsj-2017-003.

Smith, A., and J. Matthews, 2015: Quantifying uncertainty and variable sensitivity within the U.S. billion-dollar weather and climate disaster cost estimates. Nat. Hazards, 77, 1829-1851, https://doi.org/10.1007/s11069-015-1678-x.

Stevenson, H., and J. Dryzek, 2012: The legitimacy of multilateral climate governance: A deliberative democratic approach. Crit. Policy Stud., 6 (1), 1-18, https://doi.org/ 10.1080/19460171.2012.659879.

Stöckle, C. O., and Coauthors, 2018: Evaluating opportunities for and increased role of winter crops as adaptation to climate change in dryland cropping systems of the US inland Pacific Northwest. Climatic Change, 146, 247-261, https://doi.org/ 10.1007/s10584-017-1950-z.

Tengö, M., R. Hill, P. Malmer, C. M. Raymond, M. Spierenburg, F. Danielsen, T. Elmquist, and C. Folke, 2017: Weaving knowledge systems in IPBES, CBD, and beyond-Lessons learned for sustainability. Curr. Opin. Environ. Sustain., 26-27, 17-25, https://doi.org/10.1016/j.cosust.2016.12.005.
Vinyeta, K., and K. Lynn, 2013: Exploring the role of traditional ecological knowledge in climate change initiatives. USDA Forest Service General Tech. Rep. PNW-GTR-879, 37 pp., https://doi.org/10.2737/PNW-GTR-879.

Vose, J. M., J. S. Clark, C. H. Luce, and T. Patel-Weynand, 2016: Effects of drought on forests and rangelands in the United States: A comprehensive science synthesis. USDA Forest Service General Tech. Rep. WO-93b, 302 pp., https://doi.org/ 10.2737/WO-GTR-93b.

— , and Coauthors, 2018: Forests. Impacts, Risks, and Adaptation in the United States: Fourth National Climate Assessment, Vol. II, D. R. Reidmiller et al., Eds., U.S. Global Change Research Program, 232-267.

- D. L. Peterson, C. H. Luce, and T. Patel-Weynand, 2019: Effects of drought on forests and rangelands in the United States: Translating science into management responses. USDA Forest Service General Tech. Rep. WO-98, 227 pp., https://doi.org/10.2737/WO-GTR-98.

Whyte, K. P., 2017: Systematic discrimination in peer review: Some reflections. Daily Nous, accessed 9 April 2019, http:// dailynous.com/2017/05/07/systematic-discrimination-peerreview-reflections/.

Williams-Rajee, D., and T. Evans, 2016: The integration of equity in the Portland/Multnomah County 2015 Climate Action Plan. City of Portland and Multnomah County, accessed 5 May 2019, https://www.portlandoregon.gov/bps/article/583501.

Wuebbles, D. J., D. W. Fahey, K. A. Hibbard, D. J. Dokken, B. C. Stewart, and T. K. Maycock, Eds., 2017: Climate Science Special Report: Fourth National Climate Assessment. Vol. I, U.S. Global Change Research Program, 470 pp., https:// doi.org/10.7930/J0J964J6.

Yamineva, Y., 2017: Lessons from the intergovernmental panel on climate change on inclusiveness across geographies and stakeholders. Environ. Sci. Policy, 77, 244-251, https://doi.org/ 10.1016/j.envsci.2017.04.005.

Yorgey, G., and Coauthors, 2017: Agriculture in a changing climate: Research and extension priorities in the Northwest. Front. Ecol. Evol.: Agroecol. Land Use Syst., 5, 52, https:// doi.org/10.3389/FENVS.2017.00052. 